\title{
Can healthy life style predict successful aging among Iranian older adults?
}

\author{
Mohsen Shafiee**1,2, Maryam Hazrati*3,4 ${ }^{(\mathbb{D}}$, Seyedeh Ameneh Motalebi**5, Sakineh Gholamzade ${ }^{3}$, Haleh Ghaem $^{6}$, \\ Asmidawati Ashari ${ }^{7}$
}

Received: 10 Oct 2019

Published: 19 Oct 2020

\section{Abstract}

Background: Successful aging is a prominent and worldwide theme in gerontology. However, until recently, only few studies were conducted about successful aging in Iran. This study examined whether a healthy lifestyle could predict successful aging among older Iranians.

Methods: This cross sectional and descriptive study included 975 older Iranians who were selected through a multistage cluster-quota method from the health centers of Shiraz, Iran. A 5-part questionnaire, including demographic characteristics, the Seniors' Healthy Lifestyle, Barthel Index, the Diner Life Satisfaction and Quality of Life, was used to collect the data. A logistic regression analysis was used in data analysis; data were analyzed using SPSS 21; and significance level was set at $\alpha=0.05$.

Results: The prevalence of successful aging among older Iranians was calculated at $24.0 \%$. Results of multiple logistic regression analysis revealed that age $(95 \% \mathrm{CI}=1.129-1.702$ and $\mathrm{OR}=1.352)$, gender $(95 \% \mathrm{CI}=0.412-0.764$ and $\mathrm{OR}=0.687)$, education level $(95 \% \mathrm{CI}=1.443-1.699$ and $\mathrm{OR}=1.454)$, job $(95 \% \mathrm{CI}=1.063-1.413$ and $\mathrm{OR}=1.185)$, monthly income $(95 \% \mathrm{CI}=1.355-4.055$ and $\mathrm{OR}=2.272)$, insurance $(95 \% \mathrm{CI}=0.344-0.842$ and $\mathrm{OR}=0.540)$, source of income $(95 \% \mathrm{CI}=1.014-1.298$ and $\mathrm{OR}=1.145)$, and healthy lifestyle $(95 \% \mathrm{CI}=0.772-0.858$ and $\mathrm{OR}=0.814)$ were predictors for successful aging.

Conclusion: Findings indicated that successful agers were mostly younger men, with higher education level and monthly income, who had insurance and a job and a healthy lifestyle. Thus, to age successfully, one must maintain and improve healthy lifestyle to prolong one's health.

Keywords: Healthy lifestyle, Prevalence, Successful aging

Conflicts of Interest: None declared

Funding: This article was extracted from a research project that was supported financially by Shiraz University of Medical Sciences.

\section{*This work has been published under CC BY-NC-SA 1.0 license.}

Copyright $\odot$ Iran University of Medical Sciences

Cite this article as: Shafiee M, Hazrati M, Motalebi SA, Gholamzade S, Ghaem H, Ashari A. Can healthy life style predict successful aging among Iranian older adults? Med J Islam Repub Iran. 2020 (19 Oct);34:139. https://doi.org/10.47176/mjiri.34.139

\section{Introduction}

Aging populations pose a challenge in both developed

Corresponding author: Dr Maryam Hazrati, hazratim@sums.ac.ir

**The third and first authors contributed equally to this manuscript

1. Department of Nursing Geriatric, Nursing and Midwifery School, Shiraz University of Medical Sciences, Shiraz, Iran

2. Department of nursing, Abadan University of Medical Sciences, Abadan, Iran

3. Community Based Psychiatric Care Research Center, Shiraz University of Medical Sciences, Shiraz, Iran

4. Deputy Ministry of Nursing Affaires, Ministry of Health and Medical Education, Tehran, Iran

5. Social Determinants of Health Research Center, Research Institute for Prevention of Noncommunicable Diseases, Qazvin University of Medical Sciences, Qazvin, Iran

6. Department of Epidemiology School of Health, Shiraz University of Medical Sciences. Shiraz, Iran

7. Department of Human Development and Family Studies, Faculty of Human Ecology, Universiti Putra Malaysia, Serdang, Selangor and developing countries (1). The pace of aging population

$\uparrow$ What is “already known" in this topic:

Successful aging is a worldwide concept in gerontology. Rowe and Kahn's (1997) model provides one of the most popular frameworks used in the previous researches in this area. Rowe and Kahn stated that successful aging involved 3 main factors, including being free of disability or disease, having high cognitive and physical abilities, and being active in social interactions. Furthermore, healthy lifestyle plays an important role in the prevention and control of age-related diseases. However, the association between healthy lifestyle on successful aging has not been well considered in the literature.

\section{$\rightarrow$ What this article adds:}

Rapid growth in the number of older population suggests the need to investigate the prevalence and correlated factors of successful aging. To date, little has been known about successful aging in Iran. Thus, this study aimed to identify the prevalence of successful aging and its correlates among Iranian elderly. 
around the globe is growing rapidly (2). Recently, approximately there were 600 million seniors aged 60 years and older worldwide, which is expected to increase up to 2 billion in 2050. Two thirds of these people live in developed countries, and their number will reach up to $75 \%$ in 2025 (3), Iran is no exception. The latest census indicates that the aging population in Iran has increased $1.1 \%$ from $8.2 \%$ in 2011 to $9.3 \%$ in 2016 (4).

The progress of medical sciences in the middle of the twentieth century led to a relative increase in life span worldwide and accelerated the growth of the aging population (5). Although aging is not a disease, those who are old are more susceptible to diseases and disability due to various age-related deterioration as compared to younger people. Therefore, across the life span, being old is a time period when elderly health care needs are more consideration (6). In the aging process, some factors such as loss of spouse and friends, missing children, losing a job, poverty, and losing identity may significantly affect the senior's health (7). Thus, the increasing growth in the number of elders creates significant concerns, specifically in relation to their health (8).

Nongenetic factors, particularly lifestyle, play an important role in the development of age-related diseases and aging health (9). A healthy lifestyle is an effective and modifiable factor in the seniors' health promotion $(10,11)$. It leads to a reduction in the risk of illnesses and early death (12). Healthy lifestyle includes good nutrition, healthy eating, regular physical activity, stress management, no smoking, and protective activities against the development of health issues (13). However, it was believed that the reduction of physical activity is inevitable by advancing age. In contrast, recent studies have shown that even most of the disabled seniors are able to maintain their physical activity according to their abilities and should avoid inactivity (1416). Thus, as the cohort has aged, it is important to find the role of healthy lifestyle on successful aging.

Successful aging has been defined in a variety of ways. Rowe and Kahn's model provides one of the frameworks most used in previous research. This particular model suggested a pyramid consisting of 3 important criteria for successful aging: absence of disease and disease related disability, good cognition and physical functional capacity, and active social engagement $(17,18)$. However, this model fails to address the implications of the fact that the aging process does include those with disability and diseases and a disease-free older age is unrealistic (17).

Rapid growth in the number of Iranian elders and increasing burden of chronic diseases suggest the need to investigate the well-being of this population. As the number of elders increases, concern on how to age successfully is becoming an issue that needs to be addressed. To date, no empirical information has been published on successful aging of Iranian seniors in the literature. Thus, the present study aimed to operationalize the concept and describe the prevalence of successful aging and its correlates among a sample of Iranian elderly.

\section{Methods}

This cross sectional study was conducted among seniors aged 60 years and older residing in Shiraz, Iran. A multistage sampling technique was used to obtain a representative sample. Institutional Review Board approval was obtained for this study.

For this sampling method, Shiraz, with the population of 1.5 million, was divided into 10 municipality zones. Then, 3 health centers were randomly selected from 5 to 6 health centers located in each of the zones. Seniors were recruited by simple random sampling from the list of the personal health folders of the respective health centers. Contact information for elderly people was extracted from the folders, and they were then called and invited to come to the respected health centers at a certain time if they were willing to participate in the study. We informed the seniors about the aims and procedures of the study by a telephone call.

By considering $11 \%$ prevalence of successful aging $(p=0.11)$ that was extracted from results of Gwee et al (19), and by considering alpha level $=0.05$ and degree of precision equal to 0.02 , the total sample size was calculated at 976. The number of participants was selected based on the distribution of the elderly population in each cluster. Inclusion criteria were age $\geq 60$ years, ability to communicate orally, and volunteering to participate in the study. Old people with severe physical, mental, and cognitive diseases with diagnosis of Alzheimer and severe depression were excluded from the study. From the approximately 1150 eligible elderly people, 975 (84.78\%) completed the questionnaires and participated in this study.

Informed consent was reviewed with each participant in a private room at the health center. After consent was received, a face-to-face interview was conducted from June 2014 to February of 2015 by 6 trained and qualified assessors. Each interview took approximately 40 minutes. Data collected at the interview were from 5 structured questionnaires: a demographic questionnaire, the Barthel Index of Activities of Daily Living, Diener's life satisfaction scale, the SF 36 questionnaire, and the healthy lifestyle questionnaire. Participants were given short rest periods during the interview because there were many questionnaires to be filled out. To do so, the participants blood pressure was taken.

The demographic questionnaire consisted of 7 questions that included age, gender, education level, marital status, job, income resources, history of chronic illnesses, and insurance status.

\section{The Barthel Index}

The Barthel Index of Activities of Daily Living (ADL) was introduced by Dorothea Barthel in 1955 (20). This questionnaire consists of 10 items regarding ADLs, feeding, grooming, bathing, dressing, bowel and bladder control, toilet use, ambulation, transfers, and stair climbing. The total score ranges from 0 to 100, with the higher scores representing the better ability to perform ADL. The scores between 0-20 represent total dependence for ADLs, 21-60 severe dependency, 61-90 moderate dependency, 91-99 slight dependency, and 100 total independence (21). In the study conducted by Tagharrobi et al (22), the validity of this index was confirmed and its reliability was determined at 0.82 , which was in the acceptable range. 


\section{Diener's Life Satisfaction}

This scale was developed by Diener et al to measure life satisfaction (23). The scale has 5 Likert-type items measuring the cognitive component of subjective well-being with answers ranging from 1 (completely disagree) to 7 (completely agree). The participants were asked about how much they are satisfied with their lives and how much their real life is similar to their desires. The higher scores indicate better life satisfaction. Based on the obtained scores, life satisfaction was divided into 4 categories: extremely dissatisfied (5-9), dissatisfied (10-14), slightly dissatisfied (15-19), neutral (20), slightly satisfied (21-25), satisfied (26-30), and extremely satisfied (31-35) (24). Moltafet and Azarboun (25) confirmed the validity and reliability of this questionnaire. The Cronbach's Alpha was determined at 0.83 .

\section{SF36 questionnaire}

The SF 36 was developed by Ware \& Sherburne (26) and is used for assessing the quality of person's life and health. It consists of 36 items which are divided into 8 sections: (i) vitality, (ii) physical functioning, (iii) bodily pain, (iv) general health perceptions, (v) physical role functioning, (vi) emotional role functioning, (vii) social role functioning, and (viii) mental health. These 8 subscales can be combined into 2 summative components score of physical (PCS) and mental (MCS) health. The score for each of participants for each domain varied from 0 - 100, with the higher score indicating a better quality of life and health status; also, a mean score of 50 has been identified as a normative value for all domains and the questionnaire (27). The validity and reliability of this tool have been confirmed in Iranian people $(28,29)$, and the internal consistency of these 8 subscales was between 0.43 to 0.76 . In addition, this questionnaire is able to discriminate the healthy from the unhealthy persons (30).

The seniors' lifestyle was measured by healthy lifestyle questionnaire that was prepared by Eshaghi et al (11). This questionnaire consists of 46 questions that are grouped into 5 subscales: exercise, nutrition, prevention, stress management, and social and interpersonal relationships. The validity and reliability of this questionnaire was high (Cronbach's alpha $=0.76$ ). The higher score indicates a better lifestyle and the total score is classified into 3 groups: undesirable lifestyle (scores: 42-98), medium lifestyle (99155), and ideal lifestyle (156-211) (11).

In the present study, successful aging is defined as a multidimensional construct based on the theory of Row and Khan (31). Successful agers are those with no major chronic disease, such as cancer, heart problem, diabetes, stroke, hypertension, and chronic lung disease, no physical functioning difficulty, good cognitive functioning, active engagement with life with no dementia, good perceived quality of life, and satisfaction with life $(5,16)$. The scores from the 4 scales of Barthel Index of Activities of Daily Living Diener's Life Satisfaction, the SF 36, and the Healthy Lifestyle questionnaire were matched to indicate successful aging.

The data were analyzed using Statistical Package for the Social Sciences (SPSS) version 21 (SPSS ${ }^{\circledR}$; IBM; USA) for Windows. Descriptive statistics were conducted, including frequency, percent, means, and standard deviations (SD) for quantity data. All data were assessed for normal distribution by Kolmogorov-Smirnov test. A multivariate logistic regression analysis was conducted to identify the sociodemographic and healthy lifestyle factors associated with successful aging. Significance level was set at $\alpha=$ 0.05 .

\section{Results}

A total of 975 community-dwelling seniors were included in the present study, of whom 53\% were women $(n=520)$ and $47 \%$ were men $(n=455)$. The mean age of the sample was $66.9 \pm 23.7$, with a range between 60 and 97 years (Table 1). More than half of the respondents $(n=568$, $58.3 \%)$ were illiterate and more than half $(n=682,69.9 \%)$

Table 1. Demographic characteristics of participants $(n=975)$

\begin{tabular}{|c|c|c|c|}
\hline Variable & & $\mathrm{n}$ & $\%$ \\
\hline & $60-69$ & 606 & 62.20 \\
\hline \multirow[t]{3}{*}{ Age (years) } & $70-80$ & 274 & 28.10 \\
\hline & $>80$ & 95 & 9.70 \\
\hline & Illiterate & 568 & 58.30 \\
\hline \multirow[t]{4}{*}{ Education level } & Primary and secondary & 240 & 24.60 \\
\hline & High School & 117 & 12.00 \\
\hline & College Education & 50 & 5.10 \\
\hline & Married & 682 & 69.90 \\
\hline \multirow[t]{4}{*}{ Marital status } & Single & 26 & 2.70 \\
\hline & Divorced & 14 & 1.40 \\
\hline & Widow & 251 & 25.70 \\
\hline & Unemployed & 152 & 15.60 \\
\hline \multirow[t]{5}{*}{ Employment status } & Employed & 154 & 15.80 \\
\hline & Retired & 269 & 27.60 \\
\hline & Housewife & 400 & 41.00 \\
\hline & Children & 195 & 20.00 \\
\hline & Pension & 415 & 42.60 \\
\hline \multirow[t]{2}{*}{ Source of income } & Charity & 69 & 7.10 \\
\hline & Other resources & 294 & 30.20 \\
\hline \multirow[t]{2}{*}{ Insurance } & Yes & 865 & 88.70 \\
\hline & No & 110 & 11.30 \\
\hline \multirow[t]{2}{*}{ Successful ager } & Yes & 236 & 24.00 \\
\hline & No & 739 & 76.00 \\
\hline
\end{tabular}


were married. Retirement income was the source of income for $42.6 \%(n=415)$ of the Participants.

The prevalence of successful aging (having independence in activities of daily living, life satisfaction, and high quality of life) among Iranian seniors was calculated at $24 \%$ $(n=236)$. The mean scores of the 4 instruments indicated a very good quality of life, fairly independent in basic activities of daily living, low life satisfaction, and the medium healthy lifestyle of the respondents (Table 2).

Findings from the multivariate logistic regression analysis revealed that age $(95 \% \mathrm{CI}=1.129-1.702$ and $\mathrm{OR}=$ $1.352)$, gender $(95 \% \mathrm{CI}=0.412-0.764$ and $\mathrm{OR}=0.687)$, education level $(95 \% \mathrm{CI}=1.443-1.699$ and $\mathrm{OR}=1.454)$, job $(95 \% \mathrm{CI}=1.063-1.413$ and $\mathrm{OR}=1.185)$, income resource $(95 \% \mathrm{CI}=1.014-1.298$ and $\mathrm{OR}=1.145)$, insurance status $(95 \% \mathrm{CI}=0.344-0.842$ and $\mathrm{OR}=0.540)$ and monthly income $(95 \% \mathrm{CI}=1.355-4.055$ and $\mathrm{OR}=2.272)$ were predictors of successful aging (Table 3). This indicates that successful agers were more likely to be males in a younger age group, with higher education level and monthly income, insurance, and job. The results also showed that healthy lifestyle $(95 \% \mathrm{CI}=0.772-0.858$ and $\mathrm{OR}=0.814)$ is a predictor of successful aging. All parameters of the lifestyle including social and interpersonal relationships $(95 \%$ $\mathrm{CI}=1.067-1.166$ and $\mathrm{OR}=1.115)$, stress management $(95 \%$ $\mathrm{CI}=1.099-1.266 \mathrm{OR}=1.180)$, healthy nutrition $(95 \% \mathrm{CI}=$ $1.049-1.152$ and $\mathrm{OR}=1.099)$, prevention $(95 \% \mathrm{CI}=1.024$ -
1.190) and $\mathrm{OR}=1.104)$ and physical activity, exercise, recreation and fun $(95 \% \mathrm{CI}=0.840-0.975$ and $\mathrm{OR}=0.908)$ were predictors of and related to successful aging (all $\mathrm{p}<0.001)$.

\section{Discussion}

This study was designed to determine the sociodemographic and lifestyle predictors of successful aging among older Iranians. The present study indicated that only one fourth of the seniors were classified as successful agers. Since previous studies applied different criteria to define successful aging, the wide range of successful aging prevalence has been reported (31-34). However, similar to our study, the rate of successful agers was low in studies that used multidimensional criteria to define successful aging.

Findings in the present study also indicated that the mean score of seniors' life satisfaction was lower as compared to a previous local study reported by Alipour et al (35). The differences could be related to the economic status and the income level of the respondents in our study which affected their life satisfaction. Most of the seniors were below the poverty line. Also, most participants in this study had high independence level and this may have a significant impact on the improvement of their quality of life, as the ability to function independently is an important factor in the quality of life among the seniors $(36,37)$.

Regarding the sociodemographic predictors of successful

Table 2. The descriptive data of quantitative variables

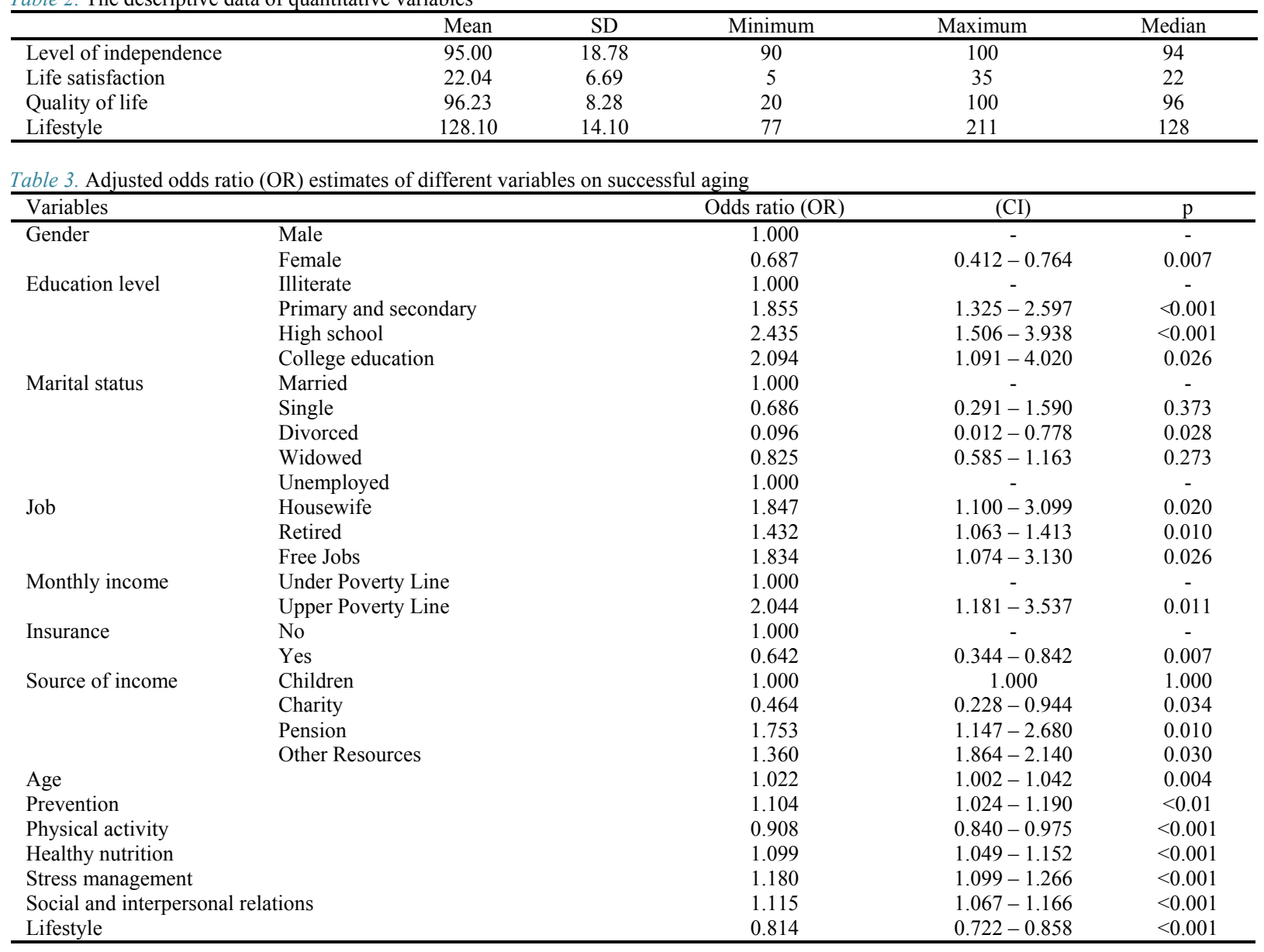


aging, this study was similar to previous studies $(38,39)$ that indicated that successful aging in Iranian older adults was related to age, gender, educational attainment, monthly income, income resource, job, and insurance. As expected and consistent with some studies $(7,38-40)$, increasing age was related to lower successful aging. This result may be related to increasing the level of dependency by advancing age (41). Our results was similar to those of Zahmatkeshan et al (42) who showed elderly men had a higher quality of life and were more likely to be successful agers. This finding may be attributed to the cultural factors. In our society, elderly men have a better social position compared to elderly women. On the other hand, elderly women are financially dependent on their husbands and they are more likely to live in poverty as compared to elderly men. Again, these factors could decrease life satisfaction and quality of life, and older women tend to be less successful. This study also found that successful aging was related to higher educational status and monthly income. This result can be explained by the fact that higher education levels provide better occupational opportunities and more financial security during old age. Furthermore, a higher level of educational attainment brings better psychological function (efficacy, happiness) (43) and optimal health behaviors (44). Increased awareness of seniors with higher education increases the probability of successful aging (45). In the present study, having a job was also found to be an effective factor for successful aging. Older people need to have a job due to low retirement income and the excessive expenses of this period of life. The lack of adequate income may increase the rate of dependency of the seniors and could reduce their self-esteem and life satisfaction as well as life quality (46).

Health insurance was another effective factor in successful aging. The results of this study showed those seniors who had social or private insurance services were more likely to be successful ager. Incidentally, Shoaei and Nejati (47) reported that social security is an important income source for the retired seniors in the United States and other developed countries. Without this source of income, two thirds of seniors will be under the poverty line. In Iran, nongovernmental organizations (NGOs) play a key role in empowerment of seniors to demand their basic health needs from the government.

The results of the logistic regression model showed that healthy lifestyle prevention, such as healthy nutrition, physical activity, social relationships, and stress management, were predictors of successful aging. In this regards, Lewis (48) found that successful aging is making a conscious decision to have a healthy lifestyle and promoting drugs and alcohol avoidance. As such, Sabia et al (49) showed that people who engaged in healthy behaviors (never smoking, moderate consumption of alcohol, engaging in some physical activity and eating fruits and vegetables daily) during midlife had greater odds of successful aging during a 16year follow-up.

Regarding prevention component, as chronic conditions had a negative relationship with successful aging $(18,50$ 52 ), the prevention of these conditions is considered to be an important factor for successful aging. Furthermore, nutrition is essential for improving the quality of life of seniors (53). Regarding physical activity, Adams-Fryatt (54) reported that engaging in regular physical activity can result in dramatic physical, mental, and social benefits for seniors. These improvements increase the quality of life, and the probability of being successful ager. In this regard, American Sports Medical College and the American Heart Association in their statement recommended that engaging in a regular exercise program for 30 minutes per day is an essential factor for successful aging (54). Furthermore, the emotionally supportive atmosphere at group exercise training programs and the positive impact of social participation cannot be underestimated.

In the present study, social relationships were related to successful aging. It seems that good social relationship is related to successful aging. Aghanouri et al (55) showed that social relationship was an effective factor in seniors' quality of life. Most of the seniors in the present study had reduced the number of their superficial relationships and increased their deep relationships. In other words, the seniors reduced the quantity of their social network but increased the quality of the relationships.

The present study was subjected to a few limitations which may provide an avenue for future studies. The first limitation of this study was that all data were collected using the self-reporting method. The second limitation was the cross sectional design of the study, which might have limited its ability to show the causal relationship among studied variables. Furthermore, the study was conducted among community-dwelling older adults, which may limit the generalization of the results to other older people or institutionalized older adults. Another limitation was that those elderly persons who were too ill to participate were not invited into the study.

\section{Conclusion}

Our findings provided the baseline information on successful aging among older Iranians. Results of this study showed that successful agers were more likely to be younger, men, with a higher education level and household income, and having income resources, insurance and job. Furthermore, all dimensions of the lifestyle were predictors of successful aging. Successful aging is multifaceted construct and we did not assess all its effective and predictive factors. Thus, other factors such as spiritual or cognitive health should be evaluated in future studies.

\section{Acknowledgment}

We would like to extend our thanks to the elderly people without whose kind cooperation this study would not have been feasible.

\section{Conflict of Interests}

The authors declare that they have no competing interests.

\section{References}

1. Reeves D, Pye S, Ashcroft DM, Clegg A, Kontopantelis E, Blakeman $\mathrm{T}$, et al. The challenge of ageing populations and patient frailty: can 
primary care adapt? BMJ. 2018;362:k3349.

2. WHO. World report on ageing and health:: World Health Organization; 2015.

3. Gurwitz JH, Pearson SD. Novel therapies for an aging population: grappling with price, value, and affordability. JAMA. 2019;321(16):1567-8.

4. Statistics Center of Iran. Estimation for number of Iranain Households by provinces and residency area from 2006 to 2016. 2016 [Available from:https://www.amar.org.ir.]

5. Berg Nvd, Rodríguez-Girondo M, de Craen AJ, Houwing-Duistermaat JJ, Beekman M, Slagboom PE. Longevity around the turn of the 20th Century: life-long sustained survival advantage for parents of today's nonagenarians. J Gerontol A Biol Sci Med Sci. 2018;73(10):1295-302.

6. Cai J CP, Zhao H. Determinants of and socio-economic disparities in self-rated health in China. Int J Equity Health. 2017;16(7):1-27.

7. Baker J, Meisner B, Logan A, Kungl A, Weir P. Physical activity and successful aging in Canadian older adults. J Aging Phys Act. 2009;17(2):223 - 35

8. Amirzadeh Iranagh J, Motalebi S, Mohammadi F. A theoretically based behavioral nutrition intervention for elderly women: A cluster randomized controlled trial. Int J Gerontol. 2017; in press.

9. Eaton NR, South SC, Gruenewald TL, Seeman TE, Roberts BW. Genes, environments, personality, and successful aging: toward a comprehensive developmental model in later life. J Gerontol A Biol Sci Med Sci. 2012;67(5):480-8.

10. Park JH, Park PY. a systematic review on factors influencing the healthy aging: A Korean perspective. J Aging Res Clin Pract. 2018;7:3-

11. Eshaghi R, Farajzadegan Z, Babak A. Designing Lifestyle Questionnaire in Elderly. Payesh J. 2009;1(9):91-99.

12. Liu YB LL, Li YF, Chen YL. Relationship between health literacy, health-related behaviors and health status: a survey of elderly Chinese. Int J Environ Res Public Health. 2015;12(8):9714-25.

13. Taghdisi M, Doshmangir P, Dehdari $T$, Doshmangir L. Factors affecting healthy lifestyle from the perspective of the elderly. Salmand. 2013;7(27):47 - 58.

14. Franklin N, Tate C. Lifestyle and successful aging: An overview. Am J Lifestyle Med. 2009;3(1):6-11.

15. Rogers NT, Marshall A, Roberts CH, Demakakos P, Steptoe A, Scholes S. Physical activity and trajectories of frailty among older adults: Evidence from the English Longitudinal Study of Ageing. PloS One. 2017;12(2):e0170878.

16. Ferreira CB, Teixeira PdS, Alves dos Santos G, Maya D, Teles A, Americano do Brasil P, et al. Effects of a 12-week exercise training program on physical function in institutionalized frail elderly. J Aging Res. 2018;2018.

17. Babak A, Davari S, Aghdak P, Pirhaj iO. Assessment of healthy lifestyle among elderly in Isfahan, Iran. Journal of Isfahan medical school 2011;29(149):1046 - 74.

18. Anthony JF HC, Scott HA, Patricia JA, Ailsa KE, Andrew M. Factors associated with successful ageing. Australas J Ageing. 2010;17(1):337.

19. Gwee X, Nyunt MSZ, Kua EH, Jeste DV, Kumar R, Ng TP. Reliability and validity of a self-rated analogue scale for global measure of successful aging. Am J Geriatr Psychiatry. 2014;22(8):829-37.

20. Barthel D. Functional evaluation: the Barthel index. Maryland State. Ortopedia, Traumatologia, Rehabilitacja. 2004;3:228.

21. Nazari H, Rashedi V, Mohammadi H, Yousefi M. Relationship between cognitive status and activities of daily living among the elderly of nursing homes. J Kermanshah Univ Med Sci. 2015;18(12):744-6.

22. Tagharrobi Z, Sharifi K, Sooky Z. Psychometric evaluation of Shah version of modified Barthel index in elderly people residing in Kashan Golabchi nursing home. Feyz. 2001;15(3):213-4.

23. Diener E. Subjective well-being. Psychol Bull. 1984;95(3):542

24. El-Gilany AH, Alam RR. Effects of Nursing Program As A life Review on Life Satisfaction And Happiness Among Elderly People. ISOR- JNHS. 2017;6(3):15-21.

25. Moltafet G, Azarboun BA. Predicts life satisfaction based on family communication pattern with the mediating role of religious motivation. Journal Psychological Methods and Models. 2015;6(20):17-36.

26. Ware Jr J, Sherbourne C . The MOS 36-item short-form health survey (SF-36): I. Conceptual framework and item selection. Med Care. 1992:473-83

27. Jenkinson C, Coulter A, Wright L. Short form 36 (SF36) health survey questionnaire: normative data for adults of working age. BMJ.
1993:306(6890):1437-40

28. Pourmomeny AA, Zargham M, Fani M. Reliability and validity of the Quality of life questionnaire in Iranian patients with lower urinary tract symptoms. Low Urin Tract Symptoms. 2018;10(1):93-100.

29. Montazeri A, Goshtasebi A, Vahdaninia M, Gandek B. The short form health survey (SF-36): translation and validation study of the Iranian version. Qual Life Res. 2005;14(3):875-82.

30. Asghar IA, Faghehi S. Validation of the SF36 health survey questionnaire in two Iranian samples. J Daneshvar Raftar. 2003;1:1-11.

31. Rowe JW, Kahn RL. Successful aging. Gerontologist 1997;37(4):433-440.32

32. Hamid TA, Momtaz YA, Ibrahim R. Predictors and prevalence of successful aging among older Malaysians. Gerontology. 2012;58(4):366-70.

33. Strawbridge WCR, Shema S, Kaplan G. Successful aging: predictors and associated activities. Am J Epidemiol. 1996;144(2):135-41.

34. Montross LP, Depp C, Daly J, Reichstadt J, Golshan SH, Moore D, et al. Correlates of self-rated successful aging among community-dwelling older adults. Am J Geriatr Psychiatry. 2006;14(1):43-51.

35. Alipour F, Sajadi H, Setare F, Beyglorian A, Jalileans A. Quality of life Tehran Region 2. Salmand. 2007;10(3):72-80.

36. Hoseinpour MEA, Piri M, Maleki M. Determinants of health-related quality of life in rural elderly people of the west of Iran: A Populationbased, Cross-Sectional Study. Int J Epidemiol Res. 2019;6(1):1-7.

37. CharandabiM MAS, Jafarabadi M, Asghari M, Tavananezhad M, Karkhane N. Predictors of health-related quality of life in Iranian women of reproductive age. Appl Res Qual Life. 2016;11(3):723-37.

38. Hamid T, Abolfathi Momtaz Y, Ibrahim R. Predictors and Prevalence of Successful Aging among Older Malaysians. Gerontology. 2012;58:366 - 70.

39. Hank K. How "successful" do older Europeans age? Findings from SHARE. J Gerontol B Psychol Sci Soc Sci. 2011;66(2):230-6.

40. Ng T, Broekman B, Niti M, Gwee X, Kua E. Determinants of successful aging using a multidimensional definition among Chinese elderly in Singapore. Am J Geriatr Psychiatry. 2009;17:407 - 16.

41. Masoumi N, Jafroudi S, Ghanbari A, Kazemnejad LE. Assessment of retired elderly's people autonomy and its affecting factors in Rasht. J Holist Nurs Midwif. 2011;21(1):46-51.

42. Zahmatkeshan N, Bagherzadeh R, Akaberian S, Yazdankhah M, Mirzaei K, Yazdanpanah S. Assessing Quality Of Life and related factors in Bushehr,s elders - 2010-2011. J Fasa Univ Med Sci. 2012;2(1):53-8

43. Jongbloed J. Higher education for happiness? Investigating the impact of education on the hedonic and eudaimonic well-being of Europeans. European Educational Research Journal. 2018:1474904118770818.47. Lawrence EM. Why Do College Graduates Behave More Healthfully Than Those Who Are Less Educated? J Health Soc Behav. 2017;58(3):291-306.

44. Lawrence EM. Why do college graduates behave more healthfully than those who are less educated? J Health Soc Behav. 2017;58(3):291306.

45. Kubzansky L, Berkman L, Glass T, Seeman T. Is educational attainment associated with shared determinants of health in the elderly? Findings from the MacArthur Studies of Successful Aging. Psychosom Med. 1998;60(5):578 - 85.

46. Cheung F, Lucas RE. When does money matter most? Examining the association between income and life satisfaction over the life course Psychol Aging. 2015;30(1):120.50.

47. Shoaei F, NeiatiW. With an overview of aged care services in the United States to Iran. Salmand. 2008;7(3):68-77.

48. Lewis J. The future of successful aging in Alaska. Int J Circumpolar Health. 2013:72

49. Sabia S, Singh-Manoux A, Hagger-Johnson G, Cambois E, Brunner E, Kivimaki M. Influence of individual and combined healthy behaviours on successful ageing. CMAJ. 2012;184(18):1985-92.

50. Bos AJ. Aging and frailty or frailty and aging? Geriatr Gerontol Int. 2016;16(7):880

51. Vellas B, Sourdet S. Prevention of frailty in aging. J Frailty Aging. 2017;6(4):174-7.

52. Hsu HC. Impact of morbidity and life events on successful aging. Asia Pac J Public Health. 2011;23(4):548-69.

53. Gopinath BFV, Kifley A, Louie JCY, Mitchell P. Association between carbohydrate nutrition and successful aging over 10 years. J. Gerontol. A Biol Sci Med Sci. 2016;71(10):1335-40.

54. Adams-Fryatt A. Facilitating successful aging: encouraging older 
adults to be physically active. J Nurse Pract. 2010;6(3):187- 92

55. Aghanouri AMM, Salehi H, Jafarian K. Quality of life of elderly people covered by health centers in urban areas, the Markazi province

2011. Salmand. 2011;6(22):20-9. 